\title{
Quality of Life and Limitations in Daily Life of Stable COPD Outpatients in a Real-World Setting in Austria - Results from the CLARA Project
}

This article was published in the following Dove Press journal: International Journal of Chronic Obstructive Pulmonary Disease

\author{
Andreas Horner $\mathbb{D}^{1-3}$ \\ Otto C Burghuber ${ }^{4}$ \\ Sylvia Hartl ${ }^{5}$ \\ Michael Studnicka ${ }^{6}$ \\ Monika Merkle ${ }^{7}$ \\ Horst Olschewski iD ${ }^{8}$ \\ Bernhard Kaiser ${ }^{1}$ \\ Eva Maria Wallner (iD) \\ Bernd Lamprecht ${ }^{1,2}$ \\ 'Department of Pulmonology, Kepler \\ University Hospital, Linz, Austria; \\ ${ }^{2}$ Faculty of Medicine, Johannes Kepler \\ University, Linz, Austria; ${ }^{3}$ Institute of \\ General, Family and Preventive Medicine, \\ Paracelsus Medical University, Salzburg, \\ Austria; ${ }^{4}$ First Department of \\ Respiratory and Critical Care Medicine, \\ and Ludwig Boltzmann Institute of COPD \\ and Respiratory Epidemiology, Otto \\ Wagner Hospital and Sigmund Freud \\ University, Medical School, Vienna, \\ Austria; ${ }^{5}$ Second Department of \\ Respiratory and Critical Care Medicine, \\ Otto Wagner Hospital and Sigmund \\ Freud University, Medical School, Vienna, \\ Austria; ${ }^{6}$ Department of Pulmonary \\ Medicine, Paracelsus Medical University, \\ Salzburg, Austria; ${ }^{7}$ Specialist Office for \\ Pulmonology Dr. Merkle, Vienna, Austria; \\ ${ }^{8}$ Division of Pulmonology, Department of \\ Internal Medicine, Medical University of \\ Graz, and Ludwig Boltzmann Institute for \\ Lung Vascular Research, Graz, Austria; \\ ${ }^{9}$ A. Menarini Pharma GmbH, Vienna, \\ Austria
}

Correspondence: Andreas Horner Kepler University Hospital, Department of Pulmonology, Krankenhausstrasse 9, Linz A402I, Austria

Tel +43 (0) $5768083-6911$

$\mathrm{Fax}+43(0) 5768083-6915$

Email andreas.horner@kepleruniklinikum.at
Background: COPD patients suffer from respiratory symptoms and limitations in daily life. We aimed to characterize the impact of disease on overall health, daily life, and perceived well-being in COPD outpatients.

Methods: We conducted a national, cross-sectional study among pulmonologists and general practitioners (GPs). The St. George's Respiratory Questionnaire for COPD patients (SGRQ-C) was used. Inclusion criteria were a physician's diagnosis of COPD and age $\geq 40$ years. Subjects with a history of lung surgery, lung cancer or COPD exacerbation within the last four weeks were excluded.

Results: Sixty-seven pulmonologists and 6 GPs enrolled 1175 COPD patients. Two hundred forty-eight of those did not fulfill GOLD criteria for COPD $\left(\mathrm{FEV}_{1} / \mathrm{FVC}<0.7\right)$ and 77 were excluded due to missing data. Finally, 850 patients $(62.8 \%$ men; mean age $66.2 \pm 0.3$ (SE) years; mean $\mathrm{FEV}_{1} \%$ pred. $51.5 \pm 0.6(\mathrm{SE})$ ) were analyzed. Last year, $55.4 \%$ reported at least one exacerbation, and $12.7 \%$ were hospitalized for COPD exacerbation. Mean SGRQ-C total score was $43.1 \pm 0.83$ (SE) and mean component scores for symptoms, activity and impacts were $55.6,55.4$ and 30.5 , respectively. Half of the patients $(50.3 \%)$ reported not being able to do any sports and $78.7 \%$ stated that their respiratory symptoms did not allow them doing anything they would like to do. In patients with less severe COPD (FEV pred $^{2} 50 \%$ and non-frequent exacerbations), global health status was overrated, ie, estimated as better by the physician than by the patient, while it was underrated in more severe COPD.

Conclusion: In Austria, the burden of disease in COPD outpatients tends to be underestimated in patients with milder airway obstruction and less exacerbations and overestimated in patients with more severe airway obstruction and frequent exacerbations. Our finding suggests that validated assessment of global health status might decrease these differences of perception.

Keywords: chronic obstructive pulmonary disease, limitations, quality of life, St. Georges Respiratory Questionnaire

\section{Background}

Chronic obstructive pulmonary disease (COPD) is a chronic and progressive disease of the airways, characterized by poorly reversible airflow limitation. COPD is typically caused by tobacco smoke or long-term exposition to noxious particles or gases. ${ }^{1}$ Although COPD is considered preventable, it still is a major cause of morbidity and mortality worldwide. Estimates indicate that 174 million people are likely to be affected by COPD, and in 2015 more than 3 million people died of COPD, corresponding to $5.7 \%$ of all deaths worldwide. ${ }^{2,3}$ When followed for ten 
years, survival of COPD patients may be as low as $57 \%{ }^{4}$ Despite extensive measures to reduce exposure to tobacco smoke and indoor and outdoor air pollution, COPD incidence remains unchanged in Europe and is increasing worldwide. $^{2,5}$

Treatment options for COPD include bronchodilators, corticosteroids, long-term oxygen or pulmonary rehabilitation. ${ }^{1}$ However, outcomes of treatment like symptom control are frequently impeded by patients' ongoing smoking and concurrent comorbid disease. ${ }^{6}$ Preserving a high quality of life (QoL) as long as possible is another major objective for COPD treatment. In addition to the measurement of respiratory symptoms, QoL questionnaires became an increasingly used tool for monitoring therapeutic interventions for COPD. Therefore, generic and diseasespecific QoL tools were created, like the St. George's Respiratory Questionnaire (SGRQ; with scores 0-100; higher scores indicating lower QoL), ${ }^{7,8}$ where a validated COPD-specific version (SGRQ-C) is available. ${ }^{9}$

SGRQ-C data collected in real-life COPD patients demonstrate that achieving an acceptable QoL is difficult. A study from India, eg, found mean SGRQ-C scores of $38.9(\mathrm{SD}=25.07),{ }^{10}$ whereas a study from Denmark found even higher values of 51.1 (19.0-79.0; minimum - maximum; SD not provided), ${ }^{11}$ both indicating severely reduced QoL. These data indicate that even high standards of medical care available as currently available in developed countries cannot secure high QoL throughout the course of COPD. Possible reasons may include shortcomings of available treatments, malfunctions of the health care system or poor compliance of patients. ${ }^{12}$ However, to answer these questions, quantitative data on QoL and the interdependence with demographics, geography and other determinants of disease are required. Though the SGRQ-C is considered a very useful tool to measure QoL by both patients and physicians, ${ }^{13}$ it is not clear if there are additional factors limiting QoL which are not covered by the SGRQ. We hypothesized that COPD patients are limited in their daily life due to their disease, and that patients and physicians differ in their view on the severity of the disease.

CLARA is a real-world study on COPD in Austria. Information on the severity of COPD, as defined by spirometry and exacerbation history, was collected in pulmonary and primary care COPD outpatients. Besides, COPD patients answered the SGRQ-C and further questions assessing their general health status and limitations of daily activities due to COPD.

\section{Methods}

\section{Study Setting and Population}

CLARA, a real-world, non-interventional observational study, was conducted in 73 pulmonologists' and general practitioners (GPs)' offices all over Austria.

Besides routine care patients were not exposed to any diagnostic or therapeutic measures. A favorable opinion was retrieved from the ethics committee of the Federal State Upper Austria (vote 1089/2018). Each GP or pulmonologist was allowed to enroll a maximum of 10 and 20 patients, respectively. These upper limits were set to improve equal distribution of patients.

Inclusion criteria were age $\geq 40$ years and a physician's diagnosis of COPD according to GOLD recommendations. ${ }^{1}$ Exclusion criteria were a history of major lung surgery or lung cancer, a COPD exacerbation within the last 4 weeks, or physical or cognitive impairment resulting in either the inability to walk or to complete the questionnaire.

\section{Study Conduct}

When patients underwent a routine clinical visit (eg, routine follow-up for COPD as recommend by the GOLD committee $^{1}$ or to retrieve a prescription for their medications), they were considered possible candidates for the study, and if so, asked to participate. In case a patient provided informed consent, the treating physician filled the physician's part of the case report form (CRF). Afterwards, the patient was given the patient's part of the CRF and they had to give additional written consent to processing of their data. When completed, the anonymized two parts of the questionnaire were united, sealed, collected by study staff and analyzed centrally.

\section{Questionnaire}

In the physician's part of the CRF the treating physician provided spirometry data ( $\mathrm{FEV}_{1} \%$ pred., $\mathrm{FEV}_{1} / \mathrm{FVC}$ ), the number of exacerbations during the last year and how often the patient was hospitalized for COPD exacerbation. Exacerbations were defined, according to GOLD, ${ }^{1}$ as acute worsening of respiratory symptoms resulting in additional therapy.

We asked the treating physician as well as the patient to provide a separate and independent estimate of the patient's global health status (excellent, good, fair, poor, very poor). We then compared the two estimates and defined what we called underrating or overrating of global health status. 
Furthermore, the patient answered the SGRQ-C according to the current manual. ${ }^{14}$ The SGRQ-C is a wellcharacterized, widely used tool to describe patient-reported health impairments specific for COPD. ${ }^{9}$ It consists of a total score and the domains' activity, symptoms and impacts on daily life. Each domain is given a score between 0 and 100, and higher scores indicate worse health status. Furthermore, questions of the SGRQ-C that were of special interest were analyzed separately.

Besides, patients were asked about wanted activities, which were limited or made impossible by COPD symptoms ("Are there any activities that you avoid because of your symptoms although they would be important for you?"). The following pre-defined answers (gardening; walking the dog; going for a walk; meeting friends; going shopping) and further free-text answers were possible. Additionally, demographics (age, sex, weight and height) and comorbidities (arterial hypertension, diabetes mellitus and cardiac disease) were asked for.

\section{Data Management and Statistics}

CLARA did not test a predefined hypothesis; therefore, estimation of sample size was neither necessary nor possible. A minimum of 500 COPD patients recruited all over Austria was considered adequate to draw meaningful conclusions with acceptable precision.

Categorical data were reported as absolute number and percentage, metric data as arithmetic mean, median, minimum and maximum. To define possible predictors of high SGRQ-C scores, multivariate analysis was done. As independent variables age, sex, BMI, smoking status, severity of COPD ( $\mathrm{FEV}_{1} \%$ pred and exacerbation history), arterial hypertension, cardiac disease, and diabetes mellitus were investigated. Significant prediction was assumed when $\mathrm{p}<$ 0.05. Data analysis was conducted in R ( $R$ : A Language and Environment for Statistical Computing; Version 3.6.0; https://www.R-project.org).

\section{Results}

Sixty-seven pulmonologists and 6 GPs contributed to this study and enrolled 1175 COPD patients. Seventy-seven patients were excluded because of missing core data (eg, sex or $\mathrm{FEV}_{1}$ ) or missing consent to processing the data. Furthermore, data from 248 patients were excluded because the spirometric criterion to define airways obstruction, and as recommended by GOLD, was not met $\left(\mathrm{FEV}_{1} / \mathrm{FVC}<0.7\right)$.

Finally, 850 patients $(62.8 \%$ men; mean age $66.2 \pm 0.3$ (SE) years; mean $\mathrm{FEV}_{1} \%$ pred. $51.5 \pm 0.6(\mathrm{SE})$ ) were analyzed (see also Table 1). $86.3 \%$ were current or former smokers, and mean BMI was $26.7 \mathrm{~kg} / \mathrm{m}^{2} \pm 0.2$ (SE). High blood pressure, diabetes mellitus or heart disease was reported in $43.9 \%, 11.9 \%$ or $21.7 \%$ of patients, respectively. $46.1 \%$ of patients had severe airflow limitation $\left(\mathrm{FEV}_{1}\right.$ pred $<50 \%$, GOLD classes 3 and 4). Female COPD patients were younger, had a slightly lower BMI, better lung function ( $\mathrm{FEV}_{1} \%$ pred), and reported more current smoking but less phlegm and heart disease (see also Table 1). Baseline data of patients by treating physicians (pulmonologists vs GPs) are presented online in Supplementary Table 1.

Mean SGRQ-C total score was $43.1 \pm 0.83$ (SE) and mean component scores were 55.6, 55.4 and 30.5 for symptoms, activity and impacts, respectively. Scores according to airflow limitation severity and history of exacerbations are presented in Figure 1. In summary, SGRQ-C total and component scores at least doubled when patients with mild COPD (GOLD 1) were compared to very severe COPD (GOLD 4). Furthermore, all scores were higher in frequent exacerbators (GOLD categories $\mathrm{C} /$ D), representing a higher symptom load and disease impact in these patients.

Half of all patients (50.3\%) reported not being able to do any sports, $17.2 \%$ could not go out for entertainment or recreation due to their disease.

$78.7 \%$ stated that their respiratory symptoms did not allow them doing anything they would like to do. The majority $(50.3 \%)$ reported one or two desired activities, which were made impossible by COPD symptoms and therefore avoided.

$55.4 \% \mathrm{had}$ at least one exacerbation in the last year, and $12.7 \%$ of all patients were hospitalized for COPD exacerbation. More than $29.7 \%$ had more than one exacerbation or had at least one exacerbation leading to hospitalization (GOLD category $\mathrm{C} / \mathrm{D}$, frequent exacerbations). Further data concerning the exacerbation history are presented in Figure 2.

In $48.7 \%$ of study participants, patients and physicians disagreed about the global health status. Global health status was estimated as better by the physician than by the patient in $29.7 \%$ (ie, overrated) and was underrated in $19.0 \%$ (global health status was estimated better by the patient than the physician).

When using the difference in rating between patients and physicians as outcome (= overrated, underrated and equally rated), overrated patients had statistically significant better lung function $\left(\mathrm{FEV}_{1}\right)$, less exacerbations and lower total SGRQ-C score. Further details are available in Figure 3. 
Table I Characteristics of the Participants

\begin{tabular}{|c|c|c|c|c|}
\hline & All & Male & Female & \multirow[t]{2}{*}{ p-value } \\
\hline & $\mathbf{N}=\mathbf{8 5 0}$ & $N=534$ & $\mathbf{N}=316$ & \\
\hline \multicolumn{5}{|l|}{ Characteristics } \\
\hline Age, mean (SE) & $66.2(0.3)$ & $66.7(0.4)$ & $65.2(0.5)$ & 0.0187 \\
\hline 40-49 years (\%) & 3.2 & 3 & 3.5 & \\
\hline $50-59$ years $(\%)$ & 21.4 & 20.4 & 23.1 & \\
\hline $60-69$ years (\%) & 38.2 & 37.1 & 40.2 & \\
\hline $70-79$ years $(\%)$ & 31.5 & 33 & 29.1 & \\
\hline$\geq 80$ years $(\%)$ & 5.7 & 6.6 & 4.1 & \\
\hline BMI, mean (SE) & $26.7(0.2)$ & $27.1(0.2)$ & $26.1(0.4)$ & $<0.001$ \\
\hline$<20.0$ (\%) & 8.8 & 5.1 & 15.1 & \\
\hline $20.0-24.9(\%)$ & 33.1 & 30.8 & 37 & \\
\hline $25.0-29.9(\%)$ & 34.1 & 39.9 & 24.1 & \\
\hline$\geq 30.0$ (\%) & 24 & 24.1 & 23.8 & \\
\hline Smoking & & & & 0.015 \\
\hline Current smoker (\%) & 30.1 & 26.9 & 35.5 & \\
\hline Former smoker (\%) & 56.2 & 59.8 & 50 & \\
\hline Never smoker (\%) & 13.8 & 13.3 & 14.5 & \\
\hline \multicolumn{5}{|l|}{ Lung function } \\
\hline FEVI/FVC (SE) & $0.55(0.01)$ & $0.54(0.01)$ & $0.55(0.01)$ & 0.203 \\
\hline FEVI\%pred. (SE) & $5 I .5(0.6)$ & $50.5(0.7)$ & $53.0(0.9)$ & 0.033 \\
\hline GOLD I - FEVI $\geq 80 \%$ pred. (\%) & 3.8 & 3.4 & 4.4 & \\
\hline GOLD $2-50 \% \leq$ FEVI $<80 \%$ pred. (\%) & 50.1 & 46.4 & 56.3 & \\
\hline GOLD $3-30 \% \leq$ FEVI < 50\% pred. (\%) & 34 & 38.2 & 26.9 & \\
\hline GOLD 4 - FEVI < 30\% pred. (\%) & 12.1 & 12 & 12.3 & \\
\hline \multicolumn{5}{|l|}{ Comorbidities } \\
\hline High blood pressure (\%) & 43.9 & 45.8 & 40.8 & 0.16 \\
\hline Diabetes mellitus (\%) & 11.9 & 11.4 & 12.7 & 0.598 \\
\hline Heart disease (\%) & 21.7 & 23.8 & 18 & 0.048 \\
\hline \multicolumn{5}{|l|}{ Symptoms } \\
\hline Cough - several days a week (\%) & 55 & 57.5 & 50.8 & 0.058 \\
\hline Phlegm - several days a week (\%) & 50 & 54.1 & 43 & 0.002 \\
\hline Dyspnea - several days a week (\%) & 78.9 & 77.4 & 81.4 & 0.178 \\
\hline
\end{tabular}

In the perspective of COPD patients, predictors of global health status were total or symptoms-component SGRQ-C score, while in the perspective of treating physicians these predictors were lung function $\left(\mathrm{FEV}_{1}\right)$, exacerbations and total SGRQ-C score.

Additionally, differences in global health rating between patients and physicians were analyzed separately for pulmonologists and GPs. $20 \%$ of all patients treated by GPs $(n=20)$ disagreed with their physicians about their global health status. Global health status was estimated as better by the GP than by the patient in $5.0 \%$ (ie, overrated) and was underrated in $15.0 \%$ (global health status was estimated better by the patient than the physician). In contrast, $49.4 \%$ of all patients treated by pulmonologists $(\mathrm{n}=812)$ disagreed with their physician about the global health status. Global health status was overrated in 30.3\% and was underrated in $19.1 \%$. The difference in disagreement between pulmonologist and GPs was statistically significant $(p=0.011)$. Further details are available in online Supplementary Figure 1.

Dyspnea was more prevalent in obese patients and patients with cardiac disease. Details are shown in Figure 4.

Regression analysis showed a significant relationship between higher total SGRQ-C score and more severe airflow limitation, frequent exacerbations, and pre-existing diabetes mellitus and cardiac disease. The results concerning the component scores are set out in Figure 5. 


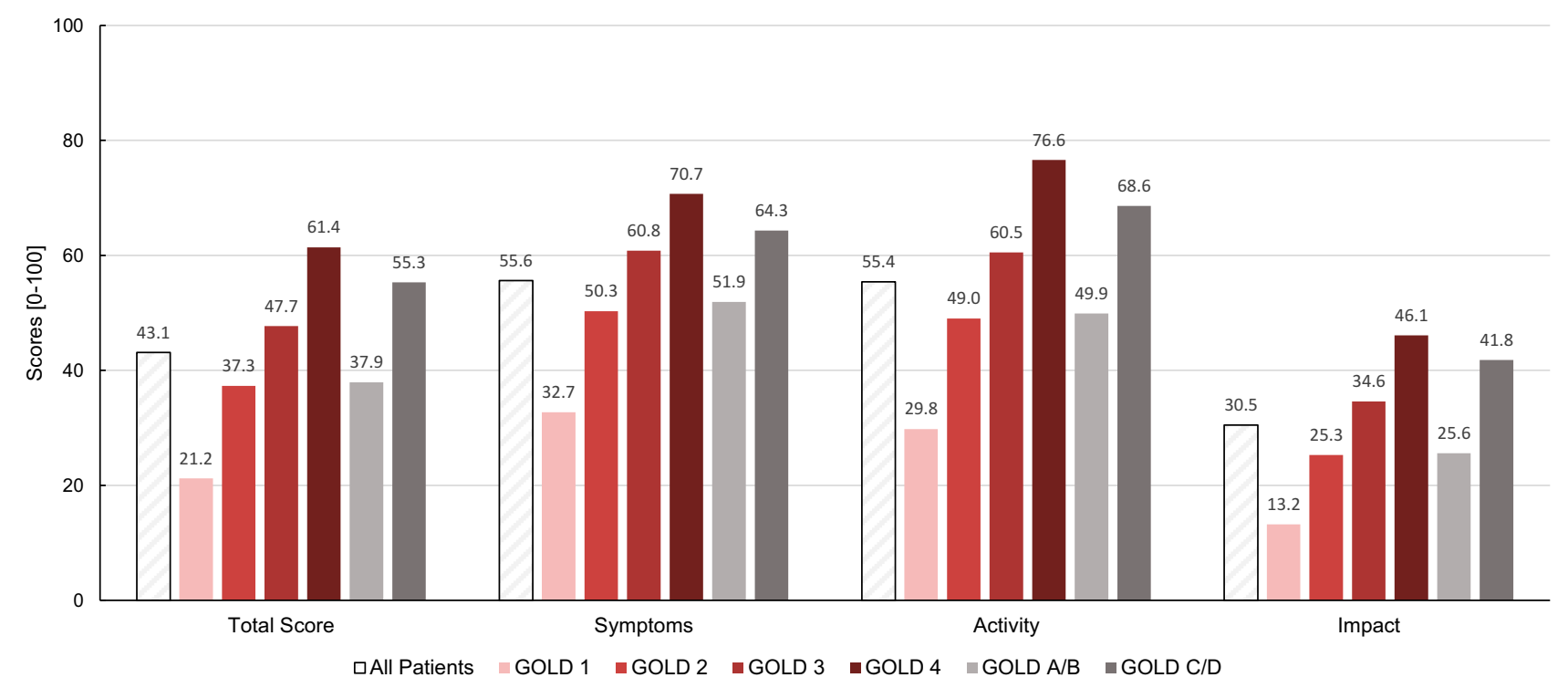

Figure I SGRQ-C (total score and component scores; scores range from 0 to 100, with higher scores indicating more limitations) by FEV $\%$ predicted (as defined by GOLD classes I-4) and by exacerbation history (as defined by GOLD classes A/B vs C/D).

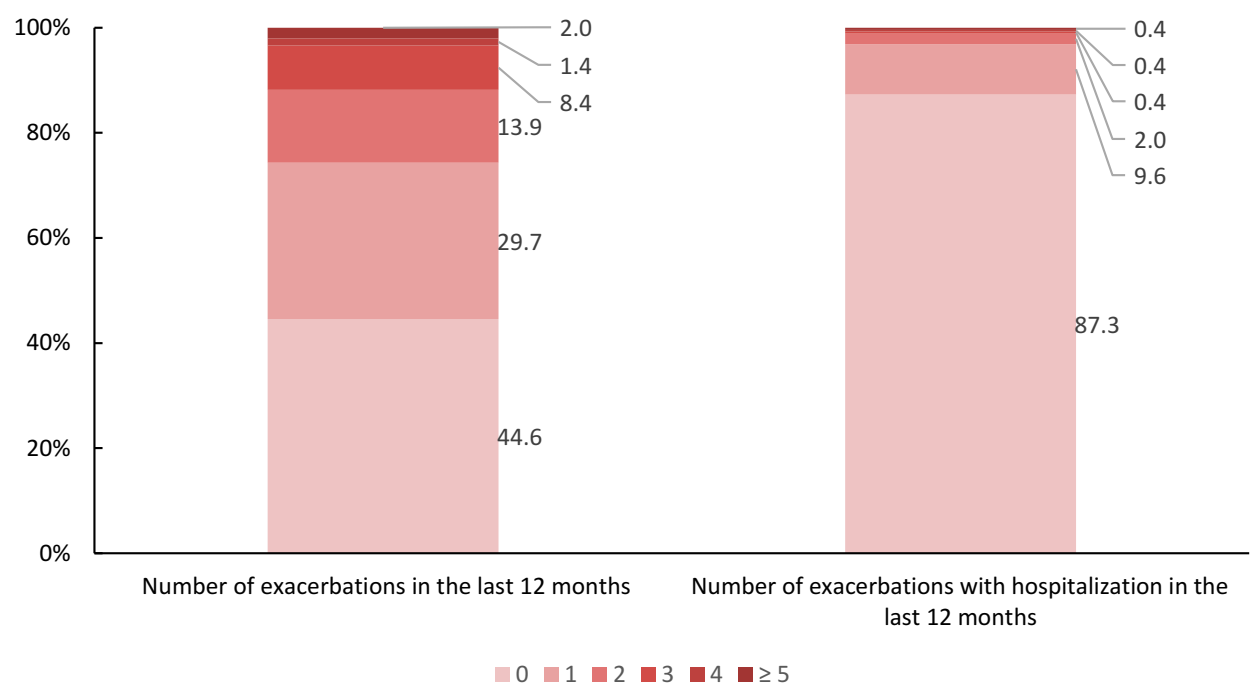

Figure 2 Number of exacerbations (with/without hospitalization) in the last 12 months (in \% of all patients).

\section{Discussion}

In Austria, real-world COPD patients report high SGRQ-C scores, indicating a high burden of symptoms and impacts in daily life of these patients. These SGRQ-C scores were found closely associated with severity of COPD, when $\mathrm{FEV}_{1}$ \%pred and exacerbation history were considered.

Similar high scores were seen in other COPD cohorts worldwide, suggesting a comparable burden due to the disease in subjects with COPD. ${ }^{15-21}$ However, we herein present the first real-life data of stable COPD patients in an outpatient setting in Austria, documenting the impact of disease on their daily life using the well-established SGRQ-C.
The majority of all patients $(50.3 \%)$ were not able to do any sports due to their disease. This may be the start of a vicious circle leading to less exercise capacity, more symptoms and even higher mortality. ${ }^{22,23}$

Discrepancies in rating the impact of COPD on patients' daily life are well documented in the literature..$^{22,24,25}$ These were also seen in our study. Interestingly, patients with more severe disease (frequent exacerbators and GOLD 3/4) rated their global health status better than their attending physicians (underrated patients). In contrast, patients with less exacerbations and spirometrically less severe disease rated their global health status worse than their attending 


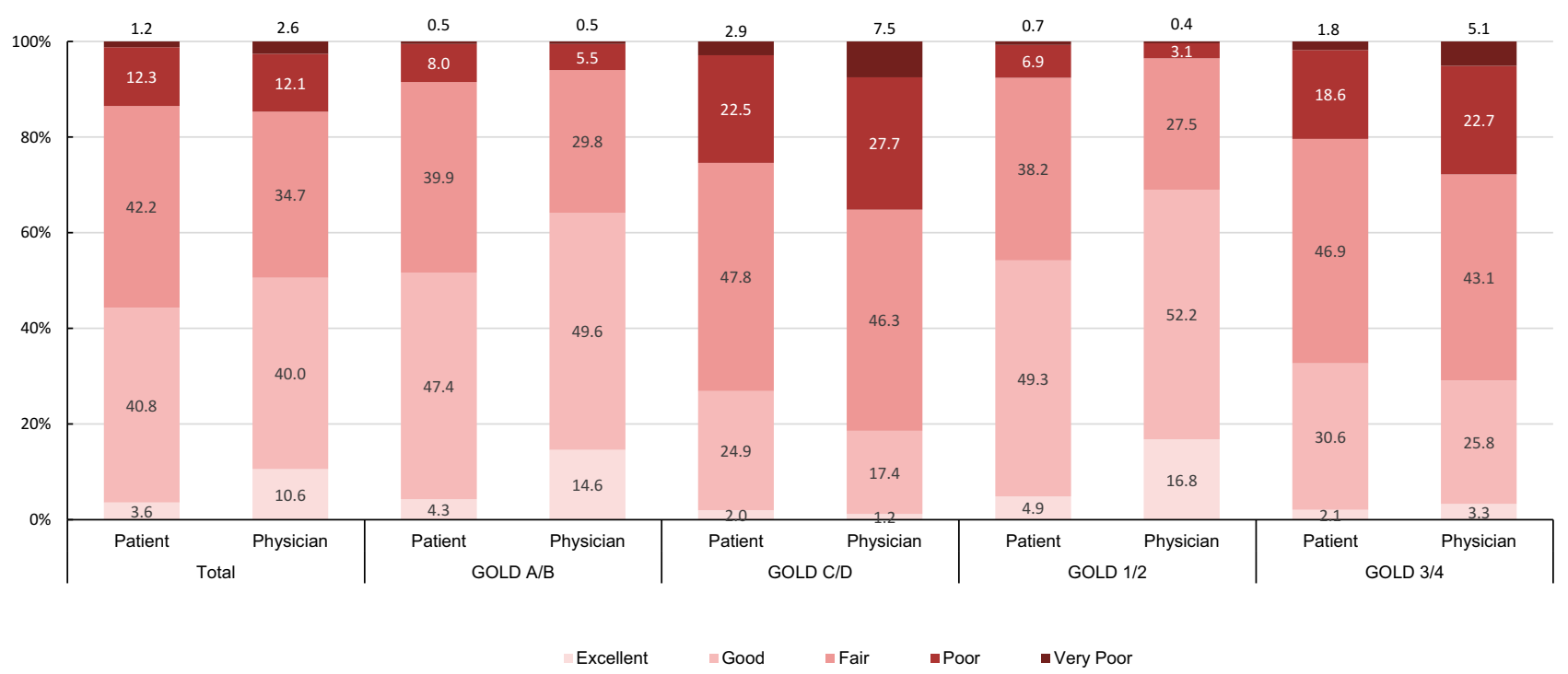

Figure 3 Global health status as estimated by patients and physicians according to severity of COPD (percentage of all patients).

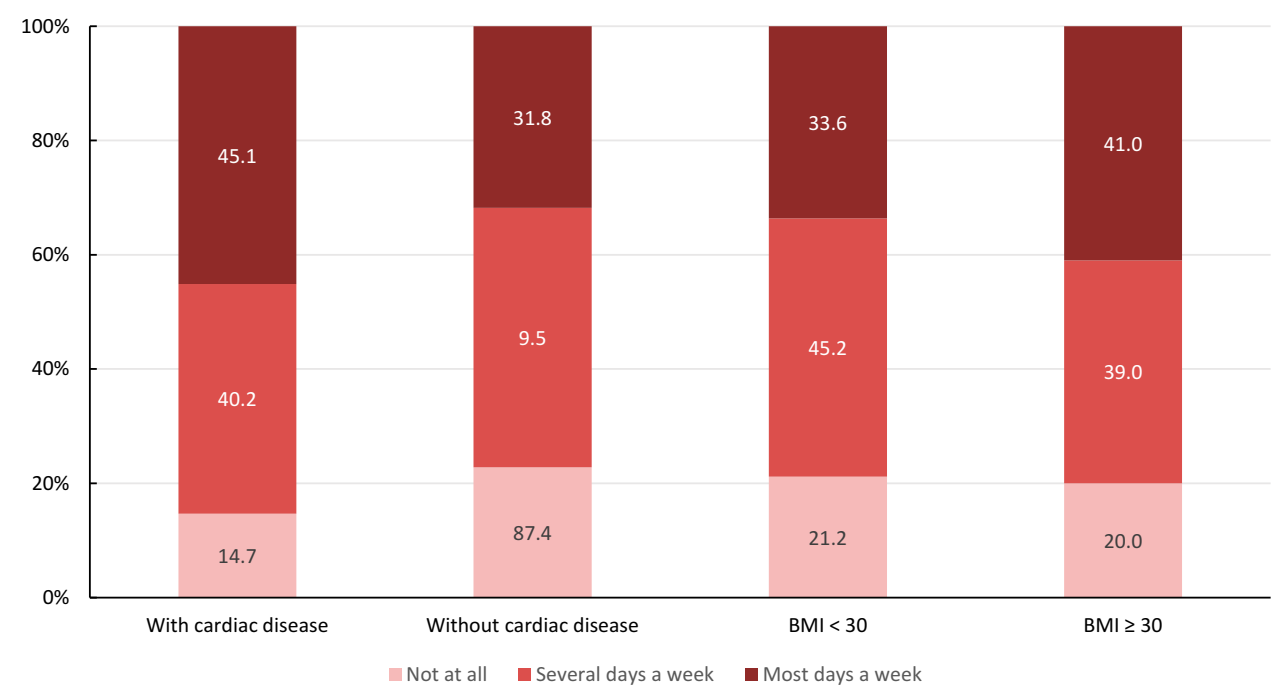

Figure 4 Dyspnea according to comorbidities (cardiac disease and obesity).

physicians (overrated patients). Hence, healthcare professionals may rely more on objective parameters such as lung function and frequency of exacerbations, whereas patients may feel a higher impact on their health status due to symptoms even in less severe disease. Interestingly, patients treated by GPs had statistically less disagreement about their global health status than patients treated by pulmonologists. Maybe this occurs as the physician-patient relationship is often closer with the GPs than the pulmonologist.

Dyspnea may be a major symptom of COPD but may be triggered also by comorbidities as obesity or cardiac disease. Obese patients and patients with cardiac disease reported suffering from dyspnea more frequently (Figure 4). In the multivariate regression analysis, the severity of airflow limitation, the history of exacerbations and diabetes mellitus or cardiac disease as comorbidities were significantly associated with a higher total SGRQ-C score. In summary, patients with more severe airflow limitation, more exacerbations or comorbidities reported more symptoms and limitations in daily life.

COPD exacerbations are common during the course of the disease. Hospitalization due to an exacerbation is not only triggered by patient factors and the severity of the disease, but also depends on the organization of the local health care system. ${ }^{26}$ In this Austrian cohort, a hospitalization rate of $12.7 \%$ in the last year is reported, comparable to other international trials. ${ }^{27,28}$ 


\begin{tabular}{|c|c|c|c|c|}
\hline & $\begin{array}{l}\text { SGRQ } \\
\text { Total }\end{array}$ & $\begin{array}{c}\text { SGRQ } \\
\text { Symptoms }\end{array}$ & $\begin{array}{c}\text { SGRQ } \\
\text { Activity }\end{array}$ & $\begin{array}{c}\text { SGRQ } \\
\text { Impact }\end{array}$ \\
\hline $\begin{array}{l}\text { Age } \\
40-49 \\
50-59 \\
60-69 \\
70-79 \\
80+\end{array}$ & $\begin{array}{l}49.6 \\
43.1 \\
40.6 \\
45.2 \\
44.5\end{array}$ & $\begin{array}{l}63.9 \\
58.7 \\
52.6 \\
56.5 \\
54.9\end{array}$ & $\begin{array}{l}58.0 \\
53.1 \\
53.4 \\
58.7 \\
59.7\end{array}$ & $\begin{array}{l}37.4 \\
30.9 \\
27.6 \\
32.8 \\
33.3\end{array}$ \\
\hline $\begin{array}{l}\text { BMI } \\
<20 \\
20-25 \\
25-30 \\
30+\end{array}$ & $\begin{array}{l}50.7 \\
42.0 \\
40.2 \\
46.7\end{array}$ & $\begin{array}{l}61.1 \\
55.7 \\
53.6 \\
56.9\end{array}$ & $\begin{array}{l}63.7 \\
53.7 \\
51.6 \\
61.8\end{array}$ & $\begin{array}{l}35.9 \\
29.7 \\
28.3 \\
33.7\end{array}$ \\
\hline $\begin{array}{l}\text { Sex } \\
\text { male } \\
\text { female }\end{array}$ & $\begin{array}{l}42.4 \\
44.3\end{array}$ & $\begin{array}{l}56.1 \\
54.8\end{array}$ & $\begin{array}{c}p=0.071 \\
53.8 \\
58.2\end{array}$ & $\begin{array}{l}30.2 \\
31.0\end{array}$ \\
\hline $\begin{array}{l}\text { Diabetes mellitus } \\
\text { no } \\
\text { yes }\end{array}$ & $\begin{array}{c}p<0.001 \\
42.1 \\
50.9\end{array}$ & $\begin{array}{c}p=0.002 \\
54.8 \\
62.2\end{array}$ & $\begin{array}{c}p<0.001 \\
54.3 \\
64.0\end{array}$ & $\begin{array}{c}\mathrm{p}<0.001 \\
29.6 \\
38.0\end{array}$ \\
\hline $\begin{array}{l}\text { Arterial hypertension } \\
\text { no } \\
\text { yes }\end{array}$ & $\begin{array}{l}42.7 \\
43.5\end{array}$ & $\begin{array}{l}56.0 \\
55.2\end{array}$ & $\begin{array}{l}55.1 \\
55.9\end{array}$ & $\begin{array}{l}30.0 \\
31.3\end{array}$ \\
\hline $\begin{array}{l}\text { Cardiac disease } \\
\text { no } \\
\text { yes }\end{array}$ & $\begin{array}{c}p<0.001 \\
41.3 \\
49.4\end{array}$ & $\begin{array}{c}p=0.006 \\
54.3 \\
60.5\end{array}$ & $\begin{array}{c}\mathrm{p}<0.001 \\
53.5 \\
62.5\end{array}$ & $\begin{array}{c}p<0.001 \\
28.8 \\
37.0\end{array}$ \\
\hline $\begin{array}{l}\text { Smoking status } \\
\text { current } \\
\text { former } \\
\text { never }\end{array}$ & $\begin{array}{l}43.4 \\
43.4 \\
38.8\end{array}$ & $\begin{array}{c}\mathrm{p}<0.001 \\
59.6 \\
55.0 \\
47.8\end{array}$ & $\begin{array}{l}52.9 \\
56.5 \\
55.0\end{array}$ & $\begin{array}{l}30.9 \\
30.8 \\
26.3\end{array}$ \\
\hline $\begin{array}{l}\text { GOLD } \\
\text { GOLD } 1 \\
\text { GOLD } 2 \\
\text { GOLD } 3 \\
\text { GOLD } 4\end{array}$ & $\begin{array}{c}\mathrm{p}<0.001 \\
21.2 \\
37.3 \\
47.6 \\
61.4\end{array}$ & $\begin{array}{c}\mathrm{p}<0.001 \\
32.7 \\
50.3 \\
60.8 \\
70.7\end{array}$ & $\begin{array}{c}\mathrm{p}<0.001 \\
37.1 \\
52.1 \\
59.3 \\
81.1\end{array}$ & $\begin{array}{c}p<0.001 \\
13.2 \\
25.3 \\
34.6 \\
46.1\end{array}$ \\
\hline $\begin{array}{l}\text { Exacerbations } \\
0,1 \\
\geq 2\end{array}$ & $\begin{array}{c}p<0.001 \\
38.8 \\
55.3\end{array}$ & $\begin{array}{c}\mathrm{p}<0.001 \\
52.4 \\
64.9\end{array}$ & $\begin{array}{c}p<0.001 \\
50.8 \\
69.0\end{array}$ & $\begin{array}{c}p<0.001 \\
26.6 \\
41.6\end{array}$ \\
\hline
\end{tabular}

Figure 5 Regression analysis - Influence of different variables on SGRQ-C total and component score (significant $[\mathrm{p}<0.05]$ variables shadowed in red).

Strength and limitations: The study used a highly standardized protocol and successfully included COPD patients from all nine Austrian federal states. Selection of participating pneumologists and GPs was not at random, leaving the possibility of differential and possibly biased selection. The decision to include COPD patients into the study was left to the individual investigator's discretion. However, comparison of baseline characteristics of the 
CLARA population regarding age, sex, and severity of disease indicates that selection bias was not a problem.

However, we were not able to address COPD patients, who were either undiagnosed or untreated for their COPD. Population-based random samples indicate that approximately $80 \%$ of COPD patients are non-diagnosed with the disease, and these patients experience different burden of disease. $^{29,30}$

As most of the data were self-reported by the patient, response biases may have occurred. Furthermore, due to the cross-sectional design, we were not able to provide any longitudinal data.

\section{Conclusions}

In Austria, stable COPD outpatients are strongly symptomatic and experience severe limitations in daily life due to their disease. The burden of disease in COPD outpatients tends to be underestimated in patients with milder airway obstruction and less exacerbations and overestimated in patients with more severe airway obstruction and frequent exacerbations. Our finding suggests that validated assessment of global health status might decrease these differences of perception.

\section{Abbreviations}

$\mathrm{BMI}$, body mass index; CRF, case report form; COPD, chronic obstructive pulmonary disease; GP, general practitioner; QoL, quality of life; SGRQ, St. George's Respiratory Questionnaire; SGRQ-C, St. George's Respiratory Questionnaire for COPD patients.

\section{Ethics Approval and Consent to Participate}

All participants provided written informed consent to participate in the study. The protocol was approved by the independent ethics committee of the Federal State Upper Austria (vote 1089/2018). This study was conducted in accordance with the Declaration of Helsinki.

\section{Acknowledgments}

The authors wish to express their gratitude to all investigators who contributed to the conduct of the CLARA study. Funding for this study was provided by A. Menarini Pharma GmbH. This funding source had no role in data analysis, interpretation of the data, or decision to submit results. Statistical and writing assistance (initial draft "Background" and "Methods") were provided by
Datamedrix GmbH (Andreas Redl), Bernhard Kaiser and CW Research \& Management GmbH (Dr. Wolfram Adlassnig). Furthermore, we would like to thank Petra Lichtenberger (Department of Pulmonology, Kepler University Hospital, Linz, Austria) for her assistance in designing the figures.

\section{Author Contributions}

$\mathrm{AH}$ had full access to all the data in the study, takes responsibility for the integrity of the data and the accuracy of the data analysis, including and especially any adverse events, and drafted the manuscript. $\mathrm{AH}, \mathrm{OCB}, \mathrm{SH}, \mathrm{MS}, \mathrm{MM}, \mathrm{HO}$, $\mathrm{BK}, \mathrm{EMW}$ and $\mathrm{BL}$ contributed to the study conception and design, data analysis and interpretation, critical revision of the manuscript for important intellectual content and final approval of the manuscript. All authors contributed to data analysis, drafting or revising the article, gave final approval of the version to be published, and agree to be accountable for all aspects of the work.

\section{Disclosure}

$\mathrm{AH}$ reports expenses for statistical analyses from A. Menarini Pharma $\mathrm{GmbH}$, Vienna Austria. SH reports grants, personal fees from Chiesi Farmacia, Astra Zeneca, GSK, Novartis, MSD, Roche, Takeda, Boehringer Ingelheim, and Menarini, outside the submitted work. MM reports personal fees from Astra-Zeneca, Berlin Chemie, Boehringer Ingelheim, Chiesi, GSK, Menarini, Novartis, and Sanofi outside the submitted work. HO reports personal fees from Actelion, Astra Zeneca, Bayer, Boehringer Ingelheim, Chiesi, GSK, Inventiva, J\&J, Menarini, MSD, Novartis, and Pfizer, outside the submitted work. EMW is an employee of A. Menarini Pharma GmbH. The authors report no other conflicts of interest in this work.

\section{References}

1. Singh D, Agusti A, Anzueto A, et al. Global strategy for the diagnosis, management, and prevention of chronic obstructive lung disease: the GOLD science committee report 2019. Eur Respir J. 2019;53 (5):1900164. doi:10.1183/13993003.00164-2019

2. GBD 2015 Chronic Respiratory Disease Collaborators. Global, regional, and national deaths, prevalence, disability-adjusted life years, and years lived with disability for chronic obstructive pulmonary disease and asthma, 1990-2015: a systematic analysis for the global burden of disease study 2015. Lancet Respir Med. 2017;5(9):691-706. doi:10.1016/S2213-2600(17)30293-X

3. Wang H, Naghavi M, Allen C. Mortality, causes of death c. global, regional, and national life expectancy, all-cause mortality, and causespecific mortality for 249 causes of death, 1980-2015: a systematic analysis for the global burden of disease study 2015. Lancet. 2016;388 (10053):1459-1544. doi:10.1016/S0140-6736(16)31012-1 
4. Miniati M, Monti S, Pavlickova I, Bottai M. Survival in COPD: impact of lung dysfunction and comorbidities. Medicine. 2014;93 (12):e76. doi:10.1097/MD.0000000000000076

5. Vasankari TM, Impivaara O, Heliovaara M, et al. No increase in the prevalence of COPD in two decades. Eur Respir J. 2010;36 (4):766-773. doi:10.1183/09031936.00178109

6. Berry CE, Wise RA. Mortality in COPD: causes, risk factors, and prevention. Copd. 2010;7(5):375-382. doi:10.3109/15412555.2010. 510160

7. Jones PW, Quirk FH, Baveystock CM, Littlejohns P. A self-complete measure of health status for chronic airflow limitation. The St. George's Respiratory Questionnaire. Am Rev Respir Dis. 1992;145(6):1321-1327. doi:10.1164/ajrccm/145.6.1321

8. Jones PW, Quirk FH, Baveystock CM. The St George's Respiratory Questionnaire. Respir Med. 1991;85(Suppl B):25-31. doi:10.1016/ S0954-6111(06)80166-6

9. Meguro M, Barley EA, Spencer S, Jones PW. Development and validation of an improved, COPD-specific version of the St. George Respiratory Questionnaire. Chest. 2007;132(2):456-463. doi:10.13 78/chest.06-0702

10. Ahmed MS, Neyaz A, Aslami AN. Health-related quality of life of chronic obstructive pulmonary disease patients: results from a community based cross-sectional study in Aligarh, Uttar Pradesh, India. Lung India. 2016;33 (2):148-153. doi:10.4103/0970-2113.177438

11. Ringbaek T, Martinez G, Lange P. A comparison of the assessment of quality of life with CAT, CCQ, and SGRQ in COPD patients participating in pulmonary rehabilitation. Copd. 2012;9(1):12-15. doi: 10.3109/15412555.2011.630248

12. Humenberger M, Horner A, Labek A, et al. Adherence to inhaled therapy and its impact on chronic obstructive pulmonary disease (COPD). BMC Pulm Med. 2018;18(1):163. doi:10.1186/s12890-018-0724-3

13. Paap MC, Lange L, van der Palen J, Bode C. Using the three-step test interview to understand how patients perceive the St. George's Respiratory Questionnaire for COPD patients (SGRQ-C). Quality Life Res. 2016;25(6):1561-1570. doi:10.1007/s11136-015-1192-3

14. St George's Respiratory Questionaire for COPD Patients (SGRQ-C) Manual; Available from: http://www.healthstatus.sgul.ac.uk/SGRQ_ download/sgrq-c-manual-april-2012.pdf. accessed 12january 2020.

15. Cleutjens F, Spruit MA, Ponds R, et al. Cognitive impairment and clinical characteristics in patients with chronic obstructive pulmonary disease. Chron Respir Dis. 2018;15(2):91-102. doi:10.1177/1479972 317709651

16. Braeken DCW, Spruit MA, Houben-Wilke S, et al. Impact of exacerbations on adherence and outcomes of pulmonary rehabilitation in patients with COPD. Respirology. 2017;22(5):942-949. doi:10.1111/ resp. 12987

17. Chai CS, Liam CK, Pang YK, et al. Clinical phenotypes of COPD and health-related quality of life: a cross-sectional study. Int J Chron Obstruct Pulmon Dis. 2019;14:565-573. doi:10.2147/COPD.S196 109
18. Lee H, Jhun BW, Cho J, et al. Different impacts of respiratory symptoms and comorbidities on COPD-specific health-related quality of life by COPD severity. Int $J$ Chron Obstruct Pulmon Dis. 2017;12:3301-3310. doi:10.2147/COPD.S145910

19. Merino M, Villoro R, Á H-V, Carmona C. Health-related quality of life of patients diagnosed with COPD in Extremadura, Spain: results from an observational study. Health Qual Life Outcomes. 2019;17 (1):189. doi:10.1186/s12955-019-1244-4

20. Jones PW, Brusselle G, Dal Negro RW, et al. Health-related quality of life in patients by COPD severity within primary care in Europe. Respir Med. 2011;105(1):57-66. doi:10.1016/j.rmed.2010.09.004

21. Wacker ME, Jörres RA, Karch A, et al. Assessing health-related quality of life in COPD: comparing generic and disease-specific instruments with focus on comorbidities. BMC Pulm Med. 2016;16 (1):70. doi:10.1186/s12890-016-0238-9

22. Mihaltan F, Adir Y, Antczak A, et al. Importance of the relationship between symptoms and self-reported physical activity level in stable COPD based on the results from the SPACE study. Respir Res. 2019;20(1):89. doi:10.1186/s12931-019-1053-7

23. Andrianopoulos V, Wouters EF, Pinto-Plata VM, et al. Prognostic value of variables derived from the six-minute walk test in patients with COPD: results from the ECLIPSE study. Respir Med. 2015;109 (9):1138-1146. doi:10.1016/j.rmed.2015.06.013

24. Mapel DW, Dalal AA, Johnson P, Becker L, Hunter AG. A clinical study of COPD severity assessment by primary care physicians and their patients compared with spirometry. Am J Med. 2015;128 (6):629-637. doi:10.1016/j.amjmed.2014.12.018

25. Burchette JE, Click IA, Johnson L, Williams SA, Morgan BT. Relationship of patient self-administered COPD assessment test to physician standard assessment of chronic obstructive pulmonary disease in a family medicine residency training program. J Patient Centered Res Rev. 2019;6(3):210-215. doi:10.17294/2330-0698.1699

26. Hartl S, Lopez-Campos JL, Pozo-Rodriguez F, et al. Risk of death and readmission of hospital-admitted COPD exacerbations: European COPD audit. Eur Respir J. 2016;47(1):113-121. doi:10.1183/13993 003.01391-2014

27. Mullerova H, Maselli DJ, Locantore N, et al. Hospitalized exacerbations of COPD: risk factors and outcomes in the ECLIPSE cohort. Chest. 2015;147(4):999-1007. doi:10.1378/chest.14-0655

28. Alcazar B, Garcia-Polo C, Herrejon A, et al. Factors associated with hospital admission for exacerbation of chronic obstructive pulmonary disease. Arch Bronconeumol. 2012;48(3):70-76. doi:10.1016/j.arbres. 2011.10.009

29. Lamprecht B, Soriano JB, Studnicka M, et al. Determinants of underdiagnosis of COPD in national and international surveys. Chest. 2015;148(4):971-985. doi:10.1378/chest.14-2535

30. Sator L, Horner A, Studnicka M, et al. Overdiagnosis of COPD in subjects with unobstructed spirometry: a BOLD analysis. Chest. 2019;156(2):277-288. doi:10.1016/j.chest.2019.01.015

\section{Publish your work in this journal}

The International Journal of COPD is an international, peer-reviewed journal of therapeutics and pharmacology focusing on concise rapid reporting of clinical studies and reviews in COPD. Special focus is given to the pathophysiological processes underlying the disease, intervention programs, patient focused education, and self management protocols. This journal is indexed on PubMed Central, MedLine and CAS. The manuscript management system is completely online and includes a very quick and fair peer-review system, which is all easy to use. Visit http://www.dovepress.com/testimonials.php to read real quotes from published authors. 